which a complete technique of cluster analysis is in preparation.

David W. Goodali

C.S.I.R.O. Division of Mathematical Statistics,

Western Australian Regional Laboratory,

Nedlands, Western Australia.

1 Williams, W. T., and Lance, G. N., Nature, 207, 159 (1965).

2 Williums, W. T., and Dale, M. B., Adv. Bot. Res., 2, 35 (1965).

${ }^{3}$ Goodall, D. W., Niture, 203, 1098 (1964).

${ }^{4}$ Goodall, D. W., Nature, 210, 216 (1966).

${ }^{5}$ Goodall, D. W., Biometries (in the press)

${ }^{6}$ Goodall, D. W., J. Gen. Microbiol., 42, 25 (1966).

\section{Rapid Method for determining Numerical Indexes for Time-course Curves}

In reporting experiments with biological processes such as abscission, germination, and dormancy, where results are observed and recorded periodically, most investigators have found it convenient to present the data as timecourse curves. While time-course curves such as those shown for abscission in Fig. 1 aro useful in indicating the initiation and the total amount of abscission, as well as the slope of the response curves (rate), they cannot readily be compared numcrically. For comparison of the results of large numbers of treatments in individual experiments, or of groups of experiments, and for statistical analyses, numerical designations are necessary. The time required for 50 or 100 per cent abscission and the percentage abscission at an arbitrary time after troatment are designations commonly used. Neither of these methods allows a satisfactory comparison of data froquently encountered in research. For example, comparison of the data represented by curves 1,2 , and 3 in Fig. 1 on the basis of the time to 50 or 100 per cent abscission is impossible as not all the curves reach either of these levels by the end of the experiment. This problem is intensified when treatments retard or inhibit abscission. Furthormore, the rolationship of the curves changes with time, and thus comparison of the percentage abscission at an arbitrary time represents only a small part of the information in the curve.

The 'abscission index' described here incorporates all the attributes of a time-course curve into a single number. The data are first plotted as time-course curves on graph paper, ruled 12 by 20 units to the inch (K. and E. No. 358-21). Each side of the graph is 5 in. and the area is

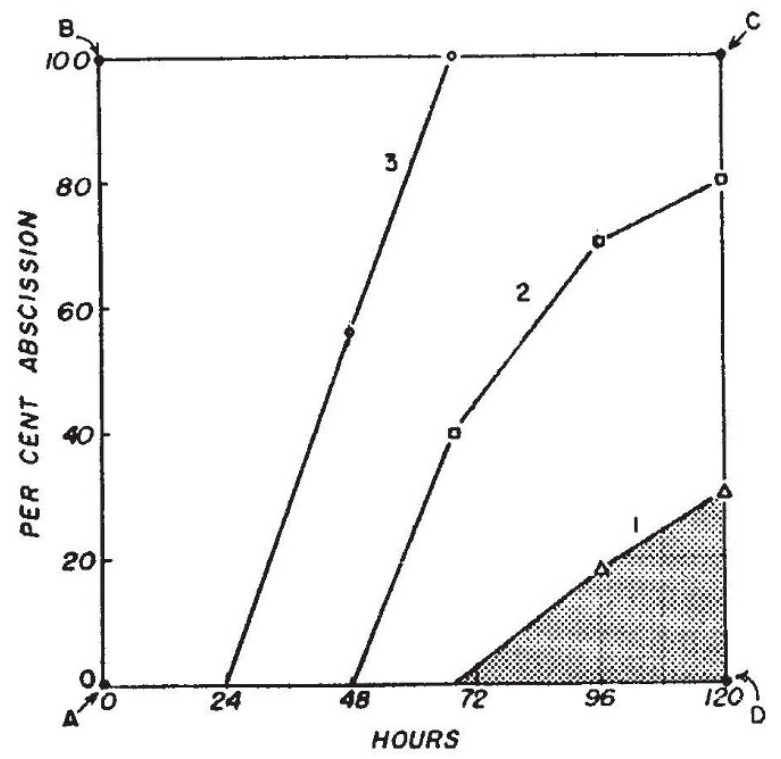

Fig. I. Time-course curves representing abscission data

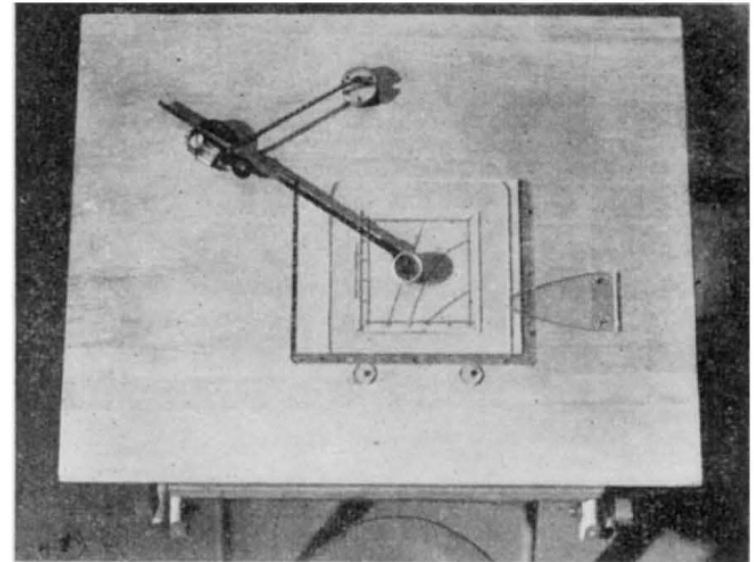

lig. 2. Apparatus used for the precision measurement of time-course curves

25 in. $^{2}$ (in Fig. 1, the area of the rectangle connecting points $A, B, C$, and $D)$. 'To obtain the index, the area under each curve (for example the shaded area under line 1) is measured with an optical planimeter (Filotecnica Salmoiraghi modol 236A). The tracer arm has been modified and adjusted to a position allowing the vernier scale roading to be exactly 100 when the area enclosed by lines connecting $A B C D$ is traced. Consequently, when any curve is traced, the vernier reading is the area under that curve expressed as per cent of the total area of $A B C D$. As the instrument is calibrated so that 25 in. ${ }^{2}$ reads 100 , the areas determined can readily be converted to any other desired units. Adjustment of the length of the planimeter tracer arm enables indexes to be obtained from various sizes and shapes of graphs; such indexes can be directly compared.

Fig. 2 is a photograph of the planimeter set up on a drawing board that has been modified to make the index determinations rapid and accurate. A section $8 \times 11.25$ in. has been removed from the centre of the board and replaced by clear 'Plexiglas' positioned over a light box. Grooves in the 'Plexiglas' allow the graph to be held in position by a vacuum produced by a small blower mounted under the board. The graph paper is positioned so that the axes are in conjunction with lines engraved on the top surface of the 'Plexiglas' inlay. An accurately machined plastic template resting against three stops serves as a guide for the lens on the end of the tracer arm. When the circumferential surface of the lens is held firmly against the inner edge of the template, the hardstone centre of the lens exactly follows the boundaries of the graph. Use of this template contributes greatly to both the speed and accuracy of the determinations.

The abscission index described is the area under a timecourse curve expressed as a percentage of the area of a rectangle of which one dimension represents 100 per cent abscission and the other dimension represents the timeduration of the experiment. This index is similar in concept to that recently described by Finlay $^{1}$, but the method described here has the advantages of versatility and speed, as well as simplicity of operation. This method and the resulting indexes are adaptable to many types of biological investigations and should prove to be a valuable rescarch tool.

\section{J. L. LYON}

Department of Agronomy,

\section{R. J. Coffelit}

Department of Agricultural Engincoring, University of California,

Davis.

${ }^{1}$ Finlay, K. W., J. Inst, Brew., 66, 51 (1960). 